\title{
The crucial roles of stimulus matching and stimulus identity in negative priming
}

\author{
COLIN M. MACLEOD \\ University of Toronto, Scarborough, Ontario, Canada \\ DAN L. CHIAPPE \\ California State University, Long Beach, California \\ and \\ ELAINE FOX \\ University of Essex, Colchester, England
}

\begin{abstract}
Negative priming refers to the situation in which an ignored item on an initial prime trial suffers slowed responding when it becomes the target item on a subsequent probe trial. In this experiment (and a replication), we demonstrate two ways in which stimulus consistency (matching) governs negative priming. First, negative priming for identical words occurred only when the prime distractor changed color when it became the probe target (i.e., constant cue to read the red word); negative priming disappeared when the prime distractor retained its color as the probe target (i.e., cue switches from read the red prime word to read the white probe word). Second, negative priming occurred for identical words, but not for semantically related words, whether related categorically or associatively. This pattern of results is consistent with a memory retrieval account, but not with an inhibition account of negative priming, and casts doubt on whether there is semantic negative priming for words.
\end{abstract}

Research over approximately the last quarter century has made it increasingly clear that selecting one item or dimension for attention can have consequences for other, unselected items or dimensions (e.g., Neill, 1977; Tipper, 1985). It is now well established that ignoring a stimulus on one trial (the prime trial) often makes it more difficult to respond to that stimulus on the subsequent trial (the probe trial). This interference can last up to several seconds (Neill \& Valdes, 1992; Tipper, Weaver, Cameron, Brehaut, \& Bastedo, 1991) and spans response modalities (e.g., Tipper, MacQueen, \& Brehaut, 1988) and even tasks (Chiappe \& MacLeod, 1995). Originally discovered by Dalrymple-Alford and Budayr (1966) in the context of the Stroop task, this effect is now called negative priming (for reviews, see Fox, 1995; May, Kane, \& Hasher, 1995). It has become one of the most widely used tasks and one of the most extensively studied phenomena in cognitive psychology and beyond.

\section{What Causes Negative Priming?}

The most widely recognized interpretation of negative priming is that task-irrelevant information is inhibited by

This research was supported by Grant A7459 from the Natural Sciences and Engineering Research Council of Canada. We thank Penny Chiappe and Penny MacDonald for their helpful input and Bruce Milliken and Trammell Neill for their excellent reviews. Correspondence about this article may be addressed to C. M. MacLeod, Division of Life Sciences, University of Toronto at Scarborough, Scarborough, ON, M1C 1A4 Canada (e-mail: macleod@utsc.utoronto.ca). the mechanisms of selective attention (Houghton \& Tipper, 1994; Neill, 1977; Tipper, 1985; Tipper \& Cranston, 1985; Tipper \& Driver, 1988; Yee, 1991). That is, when people have to selectively attend to a stimulus or stimulus dimension, their attention mechanisms simultaneously emphasize that target element and suppress the representations of task-irrelevant information. This two-process view has the benefit of highlighting the target on the prime trial but the cost of making it more difficult to use the suppressed representations shortly thereafter on the probe trial. Note that this framework allows for the possibility of semantic negative priming because inhibition can extend to representations that are semantically related to the irrelevant stimuli. One version of this theory, the behavioral goals theory of inhibition, holds that inhibitory mechanisms are flexible and can adjust to meet different situational demands. Only those properties of an array that directly compete with the target in terms of the goals to be achieved will be inhibited (Houghton \& Tipper, 1994; Tipper, 1992; Tipper, Weaver, \& Houghton, 1994). The inhibition explanation has had widespread appeal and is, to a considerable extent, responsible for the increased frequency of inhibitory explanations in cognitive psychology (see, e.g., Dagenbach \& Carr, 1994; Dempster \& Brainerd, 1995).

The other two explanations do not involve inhibition, instead relying on memory retrieval mechanisms. Under the feature mismatch theory (Park \& Kanwisher, 1994), deriving from the earlier code coordination account (Lowe, 1979), negative priming stems from a lack of correspondence between the representation of the distractor item in the prime 
display and that of the target item in the probe display. People construct representations of stimuli, including ignored items, that encompass such features as their color and size. In processing the probe display, people try to match the target item to other recently experienced items, particularly the most recently experienced item (cf. Huettel \& Lockhead, 1999, for a compelling analysis of trial sequence effects in general). A complete match can facilitate processing of the probe target. However, a partial match (e.g., representations of the ignored prime item and the target probe item differ in, say, color) can impede processing because the mismatching stimulus information must be resolved, resulting in negative priming. Note that this theory, as currently formulated, has no place for semantic negative priming: Negative priming occurs only when the identical item is associated with inconsistent properties across trials.

Neill (e.g., Neill \& Valdes, 1992; Neill, Valdes, Terry, \& Gorfein, 1992) has championed the other memory retrieval view, episodic trace theory. Here, interference results from the response conflict between the "do not respond" flag attached to the ignored prime item and the "respond" flag attached to the target probe item-the same item. When the target probe is encountered, retrieval of recent relevant information occurs, but the item most likely to be retrieved - the ignored prime item-carries with it a flag that disrupts responding to that same item, now the target probe. This account explains identity negative priming as being due to competing, inconsistent responses to the same stimulus, unlike the feature mismatch account, which emphasizes stimulus inconsistency. Unmodified, episodic trace theory would not predict semantic negative priming, which hinges on the connection between conceptually nonidentical items.

The primary goal of the experiment reported here is to provide a test of the two classes of theories of negative priming: inhibition, on the one hand, and memory retrieval (feature mismatch or episodic trace), on the other hand. To accomplish this, we manipulated the prime-probe mismatch by including two blocks of trials. In the mismatch block, subjects had to name the word written in red both in the prime display and in the probe display, which is the standard procedure in negative priming studies. We call this the mismatch block because the ignored prime seen in white became the target probe seen in red. In contrast, in the match block, subjects had to read the red word in the prime display and then read the white word in the probe display. Using this alternating color cue procedure, the ignored prime seen in white became the target probe also seen in white. ${ }^{1}$

If the inhibitory account of negative priming is correct, the word that is ignored in the prime trial will be inhibited, and processing that word in the probe trial will be more difficult. This should be true regardless of the selection color on the prime and the probe trials, because in both cases the same word will be involved. Thus, under the inhibition account, both match and mismatch blocks should show negative priming, at least for identical words. The color context on the successive prime and probe trials, an episodic element, should not influence inhibition.

If the episodic trace account of negative priming is correct, negative priming might be expected to occur in both the match and the mismatch blocks. In both cases, a response tag conflict exists between the prime and the probe trials. A proponent of the episodic trace account might argue that the contextual change from prime to probe in the match block disrupts episodic retrieval, thereby reducing or even eliminating negative priming. However, it would seem just as plausible to maintain that the identical characteristics for the critical word on the two trials in the match block should increase the likelihood of retrieval, enhancing negative priming. There is nothing intrinsic to this account that would predict any change in negative priming.

If, however, the feature mismatch explanation of negative priming is correct, negative priming should be observed in the mismatch block, but not in the match block. In the mismatch block, the ignored word in the prime display will not match the target word in the probe display: The critical word will have appeared in white during the prime trial and in red during the probe trial. Resolving this mismatch will produce negative priming. In the match block, however, the ignored prime word will be in the same color when it becomes the target probe word. Hence, there will be no mismatching feature, and nothing to resolve. This should yield no negative priming in the match block; in fact, it is even possible that positive priming would result. Only the feature mismatch account readily predicts the elimination of negative priming when the repeated item is perceptually the same from prime to probe (cf. Park \& Kanwisher, 1994).

\section{The Puzzle of Semantic Negative Priming}

Much of the research on negative priming has sought the precise locus of the effect. The consensus is that negative priming occurs at the level of a central representation of the stimulus. Thus, Tipper (1985) found that having to ignore one of two superimposed pictures in the prime display slowed the time to name the ignored picture if it reappeared as the target in the probe display. Moreover, these results extended not just to the identical picture, but to semantically related pictures as well. Hence, negative priming seems to occur at the level of the semantic representation of the ignored pictures. Indeed, recent work by MacDonald, Joordens, and Seergobin (1999) and by MacDonald and Joordens (2000) even suggests that negative priming for words can be substantially increased by emphasizing retrieval of meaning during encoding.

Using a categorization task, Tipper and Driver (1988) extended Tipper's (1985) results by obtaining negative priming for conceptually identical items. Regardless of whether the ignored stimulus on the prime trial was a word or a picture, that item caused interference if it became the target item on the probe trial. For example, ignoring a picture of a guitar during the prime trial slowed the categorization of the word guitar on the probe trial. Tipper and 
Driver also replicated the semantic negative priming for pictures that Tipper (1985) had observed between different members of a category. Intriguingly, however, they failed to observe semantic negative priming for categorically related words.

Chiappe and MacLeod (1995) included both identical words and categorically related words in the to-be-ignored condition. They manipulated the task required of subjects on the two trials, using the two most prevalent tasks in this research area: naming and categorization. Both the prime and the probe trials could require naming, both could require categorization, or one trial could require naming and the other categorization. They found robust negative priming for identical words, equivalent regardless of the task relation between the prime and the probe tasks. However, there was no negative priming for categorically related words (e.g., ignore banjo on the prime trial; respond to fiddle on the probe trial) regardless of task, even when the task was categorization on both trials.

Under what conditions does negative priming occur versus fail to occur for semantically related items? As was mentioned, semantic negative priming has been readily observed when the materials are pictures (Tipper, 1985; Tipper \& Driver, 1988); indeed, we know of only one exception (Sullivan \& Faust, 1993). Thus, it is the status of semantic negative priming for related words that remains elusive. Some experiments have yielded a semantic negative priming effect; others have not. This is the second issue that we will address in the present article.

On the positive side, Yee (1991, Experiment 1) had subjects classify geometric stimuli on the prime trial and then perform a lexical decision task on the probe trial. The prime display consisted of geometric stimuli plus one or two irrelevant words. The target in the probe display consisted of a strong associate of one of the ignored prime words, an unrelated word, or a nonword. Yee observed reliable semantic negative priming when the prime display contained two words, but not when it contained only a single word. People took longer to make a lexical decision to the single probe target word when it was associatively related to one of the two ignored prime words than when it was unrelated to both. Fox (1994, Experiment 3) replicated this finding by having people categorize a target number on the prime trial while ignoring distracting words and then make a lexical decision on the probe trial. Since then, using the same paradigm, Fox (1996) has also shown semantic negative priming for words in bilinguals. Both for associated words within and across language (Experiment 1) and for translation equivalents (Experiment 2), she found that bilinguals showed semantic negative priming. ${ }^{2}$

On the negative side, other researchers have not been able to demonstrate semantic negative priming for words. As was mentioned, Tipper and Driver (1988) failed to find significant semantic negative priming for categorically related words, as did Chiappe and MacLeod (1995). In a lexical decision task, Fuentes and Tudela (1992, Experiment 1) found semantic priming that was positive from unattended prime words when the retinal eccentricity of the distractors was fairly high $\left(4.3^{\circ}\right)$ but negative when the retinal eccentricity of the distractors was fairly low $\left(2.0^{\circ}\right)$. Moreover, other studies have failed to find any priming effects, either positive or negative, from ignored prime display items related to the target (Dark, Johnston, MylesWorsley, \& Farah, 1985; Inhoff, 1982; Inhoff \& Rayner, 1980).

Our secondary goal in this article is to explore whether the positive results obtained by some researchers arise from their use of associatively related, as opposed to categorically related, words. Both Yee (1991) and Fox (1994, 1996) used associatively related words and found semantic negative priming. However, Tipper and Driver (1988) and Chiappe and MacLeod (1995) used categorically related words and found no semantic negative priming for words. So it is possible that strongly associated words, but not categorically related words, yield semantic negative priming. By including both types of relations in the same experiment, we can make this comparison under the most nearly equivalent conditions possible. In so doing, we are responding to Fox's (1995) call for such a study: “A direct comparison between associatively and categorically related words would be informative" (p. 156).

We included three types of relations between ignored prime words and target probe words. The first was the identity condition, in which the ignored prime word was the same as the target probe word. The second was the related condition, made up of two subconditions. In the categorically related subcondition, the ignored prime word was from the same semantic category as the target probe word; in the associatively related subcondition, the target probe word was strongly associated with the ignored prime word. The third was the unrelated condition, in which the ignored prime word was neither categorically nor associatively related to the target probe. On each trial, the subjects had to say aloud the name of the cued target word, ignoring the other word in the display.

We certainly expected to find reliable identity negative priming but no semantic negative priming in the categorically related condition, thereby replicating the results of Chiappe and MacLeod (1995). If semantic negative priming does not occur for related words, as the difficulty in replicating the effect suggests, we would expect the same pattern for associated words. If, however, semantic negative priming depends on there being a strong association between words, as the Yee (1991) and Fox $(1994,1996)$ studies in which two ignored words were used suggest, we should find semantic negative priming in the associatively related condition. Our expectation was that we would find no semantic negative priming for words, regardless of their relation.

\section{METHOD}

\section{Subjects}

Forty-two undergraduates from the University of Toronto at Scarborough received bonus points in their introductory psychology course for taking part. Following Chiappe and MacLeod (1995),

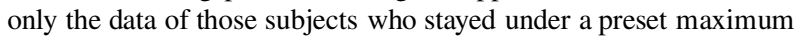


Table 1

The Experimental Conditions and Illustrations of Items in Each Condition

\begin{tabular}{|c|c|c|c|c|}
\hline \multirow[b]{2}{*}{ Condition } & \multicolumn{2}{|c|}{ Prime Trial } & \multicolumn{2}{|c|}{ Probe Trial } \\
\hline & Ignored & Target & Ignored & Target \\
\hline \multicolumn{5}{|l|}{ Unrelated } \\
\hline Categorical & banjo & stomach & dresser & pliers \\
\hline Associative & author & money & shave & baby \\
\hline \multicolumn{5}{|l|}{ Related } \\
\hline Categorical & hatchet & stomach & dresser & pliers \\
\hline Associative & cradle & money & shave & baby \\
\hline \multicolumn{5}{|l|}{ Identical } \\
\hline Categorical & pliers & stomach & dresser & pliers \\
\hline Associative & baby & money & shave & baby \\
\hline
\end{tabular}

Note-In the match block, the ignored word on the prime trial (in white) became the target word on the probe trial (in white); in the mismatch block, the ignored word on the prime trial (in white) became the target word on the probe trial (in red). Top-bottom positions of ignored and target words on each trial were randomized.

error rate of .20 in all conditions were included in the final sample. This resulted in discarding the data of 8 subjects, leaving a final sample of 34 .

\section{Apparatus}

Testing was carried out on IBM 486 compatible computers equipped with Mitsubishi 15-in. color monitors. The subjects sat approximately $40 \mathrm{~cm}$ from the screen with a Realistic Highball-7 microphone positioned close to their mouths. When a response was spoken into the microphone, the signal was amplified by a Realistic SA-150 stereo amplifier and was input through a specially modified keyboard as if the hyphen key had been pressed. All programming was done in QuickBASIC 4.5 using the millisecond-accuracy timing routines given by Graves and Bradley (1991). All materials were printed in regular lowercase font with 80 characters per line. The screen background color was black (Palate \#0); instructions were presented in blue (Palate \#9).

For one block of 80 trials, on both the prime trial and the probe trial, the target words were presented in red (Palate \#4), and the distractor words were presented in white (Palate \#15). This was the mismatch block. For the other block of 80 trials, the colors on the prime and the probe trials had different meanings. In the prime display, the target word was presented in red and the distractor in white; in the probe display, the target word was presented in white and the distractor in red. This was the match block.

\section{Stimuli}

The stimuli consisted of two sets of 10 words each. These sets were kept small because negative priming is most likely to occur with small stimulus/response sets (Malley \& Strayer, 1995). The first set consisted of 2 words from each of five semantic categories in the Battig and Montague (1969) norms, with pairs constrained not to be strong associates. The categories and words were musical instruments (banjo, fiddle), furniture (couch, dresser), tools (hatchet, pliers), body parts (heart, stomach), and animals (giraffe, mouse). These were the same words as those used by Chiappe and MacLeod (1995). The second set consisted of pairs of words strongly associated with each other but not members of the same category and were selected from the Shapiro and Palermo (1968) norms. The pairs were cradle-baby, shave-razor, bank-money, author-book, and dreamsleep. The associative words were somewhat higher in frequency than the categorical words.

\section{Procedure}

The procedural details were modeled after those of Chiappe and MacLeod (1995), but the four conditions - match associative, match categorical, mismatch associative, and mismatch categorical-were blocked rather than manipulated between subjects. Assignment to block order was counterbalanced for the first 32 subjects as follows. Sixteen subjects performed the two blocks in which the associative words were used before the two blocks in which the categorical words were used. Four did the mismatch trials first with both sets of materials, 4 did the match trials first with both sets of materials, 4 did the mismatch trials first for the associative materials but the match trials first for the categorical materials, and 4 did the mismatch trials first for the categorical materials but the match trials first for the associative materials. The same scheme was used for the 16 subjects who did the two categorical blocks first. Finally, 2 additional subjects did the categorical blocks first, 1 doing mismatch trials first for both sets of materials and 1 doing mismatch trials first for associative words and match trials first for categorical words.

Each block consisted of 10 pairs of practice trials followed by 30 pairs of experimental trials, for a total of 40 practice trial pairs and 120 experimental trial pairs. Each pair of trials consisted of a prime trial followed by a probe trial. Prime and probe words remained on the screen for $150 \mathrm{msec}$ (as in Malley \& Strayer, 1995), unlike in the Chiappe and MacLeod (1995) study, where the prime had remained visible until the subject responded. The subjects could take a break after each block, asking the experimenter to proceed once they were ready.

On each pair of trials, before the prime trial, there was a $600-\mathrm{msec}$ fixation of "+ +" in white at the center of both Rows 12 and 13 of the 25-row, 80-column screen. This warning was replaced immediately by the two-word prime display. The target word to be named on each trial was cued by its print color. To prevent the subjects from being able to focus attention in advance at the location of the target word, location of the cued word was random and equally likely to be in either the top or the bottom position. The prime trial was exposed for $150 \mathrm{msec}$. Once the subject named the prime target, there was a 500msec blank screen. This was followed by the probe trial, consisting of two words shown for $150 \mathrm{msec}$. Upon response to the probe trial, a 1-sec blank screen appeared; then the word "Ready?" appeared at the center of the screen in Row 12 until the experimenter input a keypress to indicate accuracy or to indicate a problem (i.e., a voice key failure) on one of the trials of that pair. By pressing the responsescoring key, the experimenter initiated a $1-\mathrm{sec}$ blank period prior to the onset of the next trial.

Trial pairs featured one of three types of relations between the ignored prime words and the target probe words, as is illustrated in Table 1 . In the unrelated condition, the ignored prime word was neither identical to nor semantically related to the target probe word; this was the control condition. In the identity condition, the ignored prime word was identical to the target probe word; this condition measured identity negative priming. Finally, there was the semantically related condition. Here, the ignored prime word on a given trial was the other word from the same semantically related pair as the target probe word (e.g., ignore banjo, name fiddle for the categorical set; ignore baby, name cradle for the associative set). There were 10 trial pairs in each of these three conditions within each block.

All the words in a set were used equally often in each condition. Within a single display - either the prime trial or the probe trial- the ignored word and the target word were always from different pairs within the same set. Furthermore, the ignored word in the probe display was always unrelated to both of the words in the prime display. The subjects were instructed to respond as quickly as possible to the cued word by reading it aloud, attempting to avoid errors.

\section{RESULTS}

Table 2 presents mean response times and mean proportions of errors for all conditionsin the primary experiment. The latencies are the means of individual subject untrimmed means. The errors consist of all trials on which there was an 
Table 2

Primary Experiment: Mean Response Time (RT; in Milliseconds) and Proportion of Errors (PE) as a Function of the Type of Word Relation, the Prime-Probe Color Cue Block, and the Relation Between the Ignored Prime Word and the Target Probe Word

\begin{tabular}{|c|c|c|c|c|c|c|}
\hline \multirow[b]{2}{*}{ Type of Relation } & \multicolumn{2}{|c|}{ Identical } & \multicolumn{2}{|c|}{ Related } & \multicolumn{2}{|c|}{ Unrelated } \\
\hline & RT & $\mathrm{PE}$ & RT & $\mathrm{PE}$ & RT & $\mathrm{PE}$ \\
\hline \multicolumn{7}{|c|}{ Mismatch Block } \\
\hline Categorical & 631 & .01 & 616 & .00 & 605 & .00 \\
\hline Negative priming & 26 & .01 & 11 & .00 & & \\
\hline Associative & 602 & .01 & 593 & .00 & 592 & .0 \\
\hline Negative priming & 10 & .01 & 1 & .00 & & \\
\hline \multicolumn{7}{|c|}{ Match Block } \\
\hline Categorical & 692 & .02 & 693 & .00 & 697 & .02 \\
\hline Negative priming & -5 & .00 & -4 & -.02 & & \\
\hline Associative & 683 & .03 & 680 & .01 & 684 & .00 \\
\hline Negative priming & -1 & .03 & -4 & .01 & & \\
\hline
\end{tabular}

Note-Negative priming scores (both latency and accuracy) were derived by subtracting the unrelated condition from the identical and the related conditions.

error on the prime response, the probe response, or both. The table also contains the negative priming difference scores (identical - unrelated; related - unrelated).

We first present separate analyses of the match and mismatch blocks to confirm that we found the standard negative priming result in the mismatch block and to make presentation of the data simpler to follow. Each of these initial analyses was a $3 \times 2$ repeated measures analysis of variance (ANOVA), the factors being condition (identical, related, unrelated) and item type (categorical, associative). After presenting these separate analyses, we will present the analysis that directly compares negative priming in the match and the mismatch blocks.

\section{Mismatch Block Analyses}

For comparison with the findings of Chiappe and MacLeod (1995), we first analyzed just the trials in the mismatch block; these data are shown at the top of Table 2. An analysis of the error data revealed a significant effect of condition $\left[F(2,66)=3.79, M S_{\mathrm{e}}<0.000\right.$, $p<.05]$, reflecting the negative priming in errors observed only in the identical condition. The main effect of item type and the interaction were both nonsignificant $\left(F_{\mathrm{S}}<1\right)$.

Our primary interest was in the latencies. Overall, responses to words from the categorical set $(617 \mathrm{msec})$ were $21 \mathrm{msec}$ slower than responses to words from the associative set $(596 \mathrm{msec})$, confirmed by the reliable main effect of item type $\left[F(1,33)=9.32, M S_{\mathrm{e}}=2,617.39, p<.01\right]$. This may be due to the somewhat higher frequency of the words from the associative set.

The main effect of condition was significant as well $\left[F(2,66)=5.74, M S_{\mathrm{e}}=931.16, p<.01\right]$, with responses to identical words $(616 \mathrm{msec})$ slower than those to either related words $(604 \mathrm{msec})$ or unrelated words $(598 \mathrm{msec})$. Thus, there was reliable negative priming for identical words $(18 \mathrm{msec})$, but not for related words $(6 \mathrm{msec})$.
The interaction was not significant $[F(2,66)=1.13$, $M S_{\mathrm{e}}=958.60, p>.20$ ], indicating that the same pattern was observed for both types of related words, categorically related words and associatively related words, as Table 2 clearly shows. There was reliable negative priming for identical words from both sets, but not for related words from either set. That is, for the mismatch block, there was identity negative priming but no semantic negative priming.

\section{Match Block Analyses}

The data for the trials in the match block are shown at the bottom of Table 2. An analysis of the error data revealed no significant effect of item type $(F<1)$ but a marginal interaction of item type with condition $[F(2,66)=$ $\left.2.96, M S_{\mathrm{e}}=0.001, p=.06\right]$. There did not seem to be a discernable pattern here, however. The significant effect of condition $\left[F(2,66)=5.07, M S_{\mathrm{e}}=0.002, p<.01\right] \mathrm{sug}$ gests a slightly higher error rate in the identical condition, but as will become apparent, this was manifestly not evident in the latency data.

Turning to the latency data, despite an 11-msec difference in the same direction as that observed in the mismatch block, words from the categorical set $(694 \mathrm{msec})$ were not responded to significantly more slowly than were words from the associative set $(683 \mathrm{msec} ; F<1)$ in the match block.

In sharp contrast to the mismatch block, there was no reliable effect of condition here $(F<1)$. The condition means were all within $3 \mathrm{msec}$ of each other: identical $(688 \mathrm{msec})$, related $(687 \mathrm{msec})$, and unrelated $(690 \mathrm{msec})$. Nor did item type and condition interact $(F<1)$, indicating that the two sets of items behaved equivalently. Even for the identical items, then, there was no negative priming in the match block, as Table 2 clearly shows. The possibility of positive priming when the ignored prime item and the target probe item agreed in color also was disconfirmed.

\section{Match Versus Mismatch Analyses}

To confirm that the negative priming in the mismatch blocks was greater than that in the match blocks, $2 \times 2$ ANOVAs were conducted on the negative priming difference scores, with the factors of block (match vs. mismatch) and item type (associative vs. categorical). The analysis for identical words showed only a reliable effect of block $\left[F(1,33)=6.42, M S_{\mathrm{e}}=2,265.72, p<.05\right]$; both the effect of item type and the interaction were nonsignificant $\left(F_{\mathrm{S}}<1.49\right)$. Thus, identical items did show negative priming in the mismatch block but did not in the match block. A corresponding analysis for related words produced no significant effects (all three $F_{\mathrm{S}}<1$ ), indicating no negative priming for related words regardless of cue block.

\section{Replication}

Table 3 presents a complete replication of this experiment with a sample size of $30 .^{3}$ There were some differ- 
Table 3

Replication: Mean Response Time (RT; in Milliseconds) and Proportion of Errors (PE) as a Function of the Type of Word Relation, the Prime-Probe Color Cue Block, and the Relation Between the Ignored Prime Word and the Target Probe Word

\begin{tabular}{|c|c|c|c|c|c|c|}
\hline \multirow[b]{2}{*}{ Type of Relation } & \multicolumn{2}{|c|}{ Identical } & \multicolumn{2}{|c|}{ Related } & \multicolumn{2}{|c|}{ Unrelated } \\
\hline & RT & $\mathrm{PE}$ & RT & PE & RT & PE \\
\hline \multicolumn{7}{|c|}{ Mismatch Block } \\
\hline Categorical & 542 & .04 & 527 & .02 & 529 & .04 \\
\hline Negative priming & 13 & .00 & -2 & -.02 & & \\
\hline Associative & 515 & .03 & 491 & .03 & 489 & .02 \\
\hline Negative priming & 26 & .01 & 2 & .01 & & \\
\hline \multicolumn{7}{|c|}{ Match Block } \\
\hline Categorical & 600 & .06 & 601 & .08 & 596 & .07 \\
\hline Negative priming & 4 & -.01 & 5 & .01 & & \\
\hline Associative & 578 & .09 & 569 & .06 & 576 & .07 \\
\hline Negative priming & 2 & .02 & -7 & -.01 & & \\
\hline
\end{tabular}

Note-Negative priming scores (both latency and accuracy) were derived by subtracting the unrelated condition from the identical and the related conditions.

ences in procedure, most notably (1) intermingling the categorical trials with the associative trials, (2) completing all of the mismatch trials before beginning the match trials, and (3) performing 40 experimental trials in each block, rather than 30. Otherwise, the two experiments were very similar in procedure. Despite these differences, the same pattern emerged: There was reliable negative priming in the mismatch block in the identical condition $(20 \mathrm{msec})$, but not in the related condition $(0 \mathrm{msec})$; in contrast, there was no negative priming in the mismatch block in either the identical condition $(3 \mathrm{msec})$ or the related condition $(-1 \mathrm{msec})$. ANOVAs corresponding to those for the primary experiment supported precisely the same conclusions.

\section{DISCUSSION}

\section{The Color Cue Theoretical Test}

The primary goal of this experiment was to provide a test of the two dominant classes of theories: inhibition and memory retrieval. This was accomplished by using the match versus mismatch color cue manipulation. In typical studies, the target is the same color on every trial, both prime and probe. As a consequence, the ignored item on the prime trial that becomes the target on the probe trial changes color between the trials, in addition to being responded to on the probe trial, but not on the prime trial. There are, therefore, typically two mismatches, one regarding stimulus appearance and one regarding response necessity. The episodic trace account and the feature mismatch account both maintain that the reason for negative priming is that retrieval of the ignored prime item, routinely done when it reappears as the target probe item, produces a conflict. Under the episodic trace view, this is a response conflict that would be expected to persist regardless of the color change, so that negative priming should also persist. Under the feature mismatch view, negative priming should dissipate, if not vanish altogether, when the color mismatch for the critical item is eliminated.
What we observed with regard to this cuing manipulation was clear: Negative priming occurred in the mismatch block, but not in the match block. This outcome is entirely consistent with the feature mismatch account just outlined. MacDonald et al. (1999) have reported a similar result in their studies of a novel negative priming task in which subjects had to compare the target and distractor on each trial (i.e., not ignoring either item on either the prime trial or the probe trial). Moreover, Fox and de Fockert (1998) have presented evidence that negative priming is largest when the prime and the probe displays are the most similar (see also Neill, 1997).

The inhibition account has no straightforward basis for predicting the absence of negative priming on the match trials: It would predict negative priming under both conditions. What is inhibited is the representation of the word, not something to do with its episodic status. Indeed, any attempt to modify the inhibition account to handle this result would seem to blur the distinction between the inhibition account and the two memory retrieval accounts. ${ }^{4}$ The episodic trace account also does not provide a basis for the elimination of negative priming by our manipulation: The conflict between the "do not respond" tag on the ignored prime item and the "respond" demand on the target probe item (the same item) is there regardless of item color. Only the feature mismatch view readily predicts the elimination of negative priming when feature mismatch, a key element in the standard negative priming design, is abolished.

To our knowledge, there are very few conflicting results in the literature. Tipper and Cranston (1985, Experiment 4) reported reliable negative priming for an ignored letter in a color-switch condition analogous to ours. As well, Tipper, Weaver, and Milliken (1995) reported significant negative priming in some match cases, although the magnitude clearly was reduced relative to the more standard mismatch cases. Milliken, Tipper, and Weaver (1994) found that under some cuing conditions, negative priming appeared to be determined by feature mismatches, but not under other cuing conditions. At present, we do not have an explanation for these inconsistencies.

Whether semantic negative priming exists might seem to be relevant to theory testing. On the surface, evidence against semantic negative priming would appear to be more damning for the inhibition view (Tipper, 1992; Tipper et al., 1994), given its emphasis on inhibiting representations. But representations are just as relevant to the feature mismatch (Park \& Kanwisher, 1994) and episodic trace (Neill \& Valdes, 1992; Neill et al., 1992) theories. Both of these views emphasize a representation's being flagged with two different contexts that conflict at the time of retrieval during the probe trial. Thus, the question of whether semantic negative priming occurs is wholly orthogonal to which class of mechanisms causes negative priming.

\section{Semantic Negative Priming}

Chiappe and MacLeod (1995) kept the color cue consistent on the prime and the probe trials, like the mismatch 
condition in the present study. Using categorized words in a naming task, they observed $17 \mathrm{msec}$ of negative priming for the identity condition but $0 \mathrm{msec}$ for the related condition. Using the same categorical set, we replicated this pattern of negative priming: for the identity condition, $26 \mathrm{msec}$ in the main experiment and $13 \mathrm{msec}$ in the replication $(M=20 \mathrm{msec})$; for the related condition, only 11 and $-2 \mathrm{msec}$, respectively $(M=4 \mathrm{msec})$. Thus, both the previous study and this one have shown identity negative priming, but not semantic negative priming, for categorical words. The present study extended this negative priming pattern to associative words in the mismatch cuing procedure: in the identity condition, $10 \mathrm{msec}$ in the main experiment and $26 \mathrm{msec}$ in the replication $(M=18 \mathrm{msec})$; in the related condition, only $1 \mathrm{msec}$ in the main experiment and $2 \mathrm{msec}$ in the replication $(M=2 \mathrm{msec})$. For the two most frequently studied semantic relations between words, then, there appears to be no semantic negative priming.

There remains some conflict in the literature on semantic negative priming for words: Yee (1991) and Fox $(1994,1996)$ obtained semantic negative priming with associated words, although replication has proved elusive. One critical factor may be that two words had to be ignored on the prime trial in the Yee and Fox studies. When Yee had subjects ignore only one word, she did not observe semantic negative priming. Unfortunately, we have no explanation for why increasing the number of ignored words should introduce semantic negative priming, particularly given that it has now been shown that negative priming can occur with only a single prime word (i.e., no selection required; Milliken, Joordens, Merikle, \& Seifert, 1998). At this point, our inclinationis to take the difficulty in replicating reliable semantic negative priming for words, together with our repeated failures to obtain the effect, as indicating that there is no negative priming for semantically related words.

With respect, then, to semantic negative priming for words, we have shown in a direct comparison that neither categorically related nor associatively related words produce negative priming, despite the same sets of words' reliably producing typical levels of identity priming. Of course, it could be argued that the naming task did not encourage semantic processing and, hence, would not be expected to produce much semantic negative priming. From this perspective, our test of semantic negative priming for words would be seen as a weak one, despite using the same task that most other negative priming studies have used. Although we cannot refute this argument, we point to the Chiappe and MacLeod (1995) study in which the absence of semantic negative priming was demonstrated both in the naming task (which the present experiment replicates) and in the categorization task. Categorization requires semantic processing, yet semantic negative priming was no more evident under this task than under naming. Given the apparently inconsistent findings regarding semantic negative priming for words in studies other than ours, we remain to be convinced of the existence of semantic negative priming for words.

\section{Conclusions}

Many researchers appear to have reconciled Tipper and Cranston's (1985) finding (that cue reversal between the prime and the probe trials still results in negative priming) and Park and Kanwisher's (1994) finding (that cue reversal actually produces facilitation) by believing that the mechanism underlying identity negative priming is qualitatively different from that underlying location negative priming. Our results undermine this simple reconciliation.

Overall, we see our results as inconsistent with an inhibition explanation but thoroughly in keeping with a memory retrieval explanation of negative priming, particularly one that relies on stimulus similarity from trial to trial. It appears that words must be identical to produce negative priming; semantic relatedness is not sufficient. This is probably because the retrieval that underlies negative priming occurs only when the item itself is unchanged. In fact, there may be no basis for the retrieval otherwise and, hence, no negative priming for nonidentical words. Furthermore, identical words produce negative priming only when a feature changes between the prime and the probe trials. This results in a mismatch between the retrieved (prime) and the perceived (probe) information. Resolving this competition is negative priming; there is no need for the concept of inhibition. It is not previous suppression of a word that makes that word slow to respond to when it recurs. Rather, it is associating that particular word with two situations that results in time-consuming conflict resolution.

\section{REFERENCES}

Battig, W. F., \& Montague, W. E. (1969). Category norms for verbal items in 56 categories: A replication and extension of the Connecticut category norms. Journal of Experimental Psychology Monographs, $\mathbf{8 0}(3$, Pt. 2).

Chiappe, D. L., \& MacLeod, C. M. (1995). Negative priming is not task bound: A consistent pattern across naming and categorization tasks. Psychonomic Bulletin \& Review, 2, 364-369.

DAgenbach, D., \& CARR, T. H. (EDS.) (1994). Inhibitory processes in attention, memory, and language. San Diego: Academic Press.

Dalrymple-Alford, E. C., \& BudAyr, B. (1966). Examination of some aspects of the Stroop color-word test. Perceptual \& Motor Skills, 23, 1211-1214.

Dark, V. J., Johnston, W. A., Myles-Worsley, M., \& Farah, M. J. (1985). Levels of selection and capacity limits. Journal of Experimental Psychology: General, 114, 472-497.

Dempster, F. N., \& BrAinerd, C. J. (EDS.) (1995). Interference and inhibition in cognition. San Diego: Academic Press.

Fox, E. (1994). Attentional bias in anxiety: A defective inhibition hypothesis. Cognition \& Emotion, 8, 165-195.

Fox, E. (1995). Negative priming from ignored distractors in visual selection: A review. Psychonomic Bulletin \& Review, 2, 145-173.

Fox, E. (1996). Cross-language priming from ignored words: Evidence for a common representational system in bilinguals. Journal of Memory \& Language, 35, 353-370.

Fox, E., \& DE Fockert, J. W. (1998). Negative priming depends on prime-probe similarity: Evidence for episodic retrieval. Psychonomic Bulletin \& Review, 5, 107-113.

Fuentes, L. J., \& Tudela, P. (1992). Semantic processing of foveally and parafoveally presented words in a lexical decision task. Quarterly Journal of Experimental Psychology, 45A, 299-322.

Graves, R. E., \& Bradley, R. (1991). Millisecond timing on the IBM $\mathrm{PC} / \mathrm{XT} / \mathrm{AT}$ and PS/2: A review of the options and corrections for the Graves and Bradley algorithm. Behavior Research Methods, Instruments, \& Computers, 23, 377-379. 
Houghton, G., \& TipPer, S. P. (1994). A model of inhibitory mechanisms in selective attention. In D. Dagenbach \& T. H. Carr (Eds.), Inhibitory mechanisms in attention, memory, and language (pp. 53-112). San Diego: Academic Press.

Huettel, S. A., \& Lockhead, G. R. (1999). Range effects of an irrelevant dimension on classification. Perception \& Psychophysics, 61, 1624-1645.

INHoff, A. W. (1982). Parafoveal word perception: A further case against semantic processing. Journal of Experimental Psychology: Human Perception \& Performance, 8, 137-145.

Inhoff, A. W., \& RAYner, K. (1980). Parafoveal word perception: A case against semantic preprocessing. Perception \& Psychophysics, 27, 457-464.

Lowe, D. G. (1979). Strategies, context, and the mechanism of response inhibition. Memory \& Cognition, 7, 382-389.

MacDonald, P. A., \& Joordens, S. (2000). Investigation a memorybased account of negative priming: Support for selection-feature mismatch. Journal of Experimental Psychology: Human Perception \& Performance, 26, 1478-1496.

MacDonald, P. A., Joordens, S., \& Seergobin, K. N. (1999). Negative priming effects that are bigger than a breadbox: Attention to distractors does not eliminate negative priming, it enhances it. Memory \& Cognition, 27, 197-207.

Malley, G. B., \& Strayer, D. L. (1995). Effect of stimulus repetition on positive and negative identity priming. Perception \& Psychophysics, 57, 657-667.

May, C. P., Kane, M. J., \& Hasher, L. (1995). Determinants of negative priming. Psychological Bulletin, 118, 35-54.

Milliken, B., Joordens, S., Merikle, P. M., \& Seifert, A. E. (1998). Selective attention: A re-evaluation of the implications of negative priming. Psychological Review, 105, 203-229.

Milliken B., Tipper, S. P., \& Weaver, B. (1994). Negative priming in a spatial localization task: Feature mismatching and distractor inhibition. Journal of Experimental Psychology: Human Perception \& Performance, 20, 624-646.

NeILl, W. T. (1977). Inhibitory and facilitatory processes in attention. Journal of Experimental Psychology: Human Perception \& Performance, 3, 444-450.

NeILL, W. T. (1997). Episodic retrieval in negative priming and repetition priming. Journal of Experimental Psychology: Learning, Memory, \& Cognition, 23, 1291-1305.

Neill, W. T., \& VAldES, L. A. (1992). The persistence of negative priming: Steady-state or decay? Journal of Experimental Psychology: Learning, Memory, \& Cognition, 18, 565-576.

Neill, W. T., Valdes, L. A., Terry, K. M., \& Gorfein, D. S. (1992). The persistence of negative priming: II. Evidence for episodic trace retrieval. Journal of Experimental Psychology: Learning, Memory, \& Cognition, 18, 993-1000.

PARK, J., \& KANWISHER, N. (1994). Negative priming for spatial locations: Identity mismatching, not distractor inhibition. Journal of Experimental Psychology: Human Perception \& Performance, 20, 613623.

Shapiro, S. I., \& Palermo, D. S. (1968). An atlas of normative free association data. Psychonomic Monograph Supplements, 2(12, Whole No. 28), 219-250.

Sullivan, M. P., \& Faust, M. E. (1993). Evidence for identity inhibition during selective attention in old adults. Psychology \& Aging, 8, 589-598.

TiPPER, S. P. (1985). The negative priming effect: Inhibitory priming by ignored objects. Quarterly Journal of Experimental Psychology, 37A, 571-590.

TipPER, S. P. (1992). Selection for action: The role of inhibitory mechanisms. Current Directions in Psychological Science, 1, 105-109.

Tipper, S. P., \& Cranston, M. (1985). Selective attention and priming: Inhibitory and facilitatory effects of ignored primes. Quarterly Journal of Experimental Psychology, 37A, 591-611.
Tipper, S. P., \& Driver, J. (1988). Negative priming between pictures and words in a selective attention task: Evidence for semantic processing of ignored stimuli. Memory \& Cognition, 16, 64-70.

Tipper, S. P., MacQueen, G. M., \& Brehaut, J. C. (1988). Negative priming between response modalities: Evidence for the central locus of inhibition in selective attention. Perception \& Psychophysics, 43, 45-52.

Tipper, S. P., Weaver, B., Cameron, S., Brehaut, J. C., \& Bastedo, J. (1991). Inhibitory mechanisms of attention in identification tasks: Time-course and disruption. Journal of Experimental Psychology: Learning, Memory, \& Cognition, 17, 681-692.

Tipper, S. P., Weaver, B., \& Houghton, G. (1994). Behavioural goals determine inhibitory mechanisms of selective attention. Quarterly Journal of Experimental Psychology, 47A, 809-840.

Tipper, S. P., Weaver, B., \& Milliken, B. (1995). Spatial negative priming without mismatching: Comment on Park and Kanwisher (1994). Journal of Experimental Psychology: Human Perception \& Performance, 21, 1220-1229.

WARD, L. M. (1982). Determinants of attention to local and global features of visual form. Journal of Experimental Psychology: Human Perception \& Performance, 8, 562-581.

YEE, P. L. (1991). Semantic inhibition of ignored words during a figure classification task. Quarterly Journal of Experimental Psychology, 43A, 127-153.

\section{NOTES}

1. In labeling these blocks, it is difficult to avoid creating confusion. One could emphasize the subject's task, hence focusing on the relation between the prime target and the probe target. Or one could emphasize the critical item, hence focusing on the relation between the prime distractor and the probe target. We have chosen to do the latter because that relation is at the heart of negative priming. Thus, the match-mismatch distinction refers to the relation between the prime distractor and the probe target.

2. Trammell Neill informed us in his review of this article that he has been unable to replicate Yee's (1991) pattern of results, using similar procedures. In more recent work in which monolingual subjects were used, Fox (unpublished)also has failed to replicate semantic negative priming in the number classification task in two separate experiments. Taken together, these findings certainly suggest that obtaining the semantic negative priming effect with words is not straightforward.

3. This replication was actually carried out as the original experiment, but block order was intentionally confounded, with the mismatch block done first for all the subjects, because a pilot study had suggested that this helped to reduce error rates and latencies in the more difficult match condition. This confound was removed in the main experiment reported in this article. To help to make the match trials easier in the main experiment, the categorical and associative sets were blocked, and more practice was given to the subjects.

4. The inhibition account might counter with the following argument. If the requirement to task switch between the "select red" and "select white" components results in a sharing of resources between the tasks (see Ward, 1982), subjects might pay more attention to prime distractors in the match condition than in the mismatch condition. If attending to prime distractors favors fast responses to repetitions and ignoring prime distractors leads to slow responses to repetitions, a result that is halfway between positive and negative priming, which is what we observed, might be expected. One problem with this argument is that MacDonald et al. (1999) have shown that when the distractor specifically has to be compared with the target in the prime (subjects made a relative size judgment concerning two animals or two numbers), there was actually increased negative priming.

(Manuscript received August 19, 1999; revision accepted for publication November 8, 2001.) 